\title{
The Effects of Maturation Process and Hormonal Changes on Multiple Sclerosis
}

\author{
Mostafa Mohammadi* \\ Islamic Azad University of Central Tehran Branch, Department of Electrical Engineering, Iran \\ *Corresponding author: Mostafa Mohammadi, Islamic Azad University of Central Tehran Branch, Department of Electrical \\ Engineering, Iran
}

\section{ARTICLE INFO \\ Received: 㓞 September 03, 2020 \\ Published: 隠 September 22, 2020}

Citation: Mostafa Mohammadi. The Effects of Maturation Process and Hormonal Changes on Multiple Sclerosis. Biomed J Sci \& Tech Res 30(4)-2020. BJSTR. MS.ID.004981.

Abbreviations: MS: Multiple Sclerosis; GnRH: Gonadotropin-Releasing Hormone; FSH: Follicle-Stimulating Hormone; EAE: Experimental Autoimmune Encephalomyelitis; APCs: AntigenProviding Cells; SHBG: Sex Hormone Binding Globulin; CRP: C-Reactive Protein; CSF: Cerebrospinal Fluid; MRI: Resonance Imaging

\begin{abstract}
Maturation is the beginning of the process of changes in hormones in body, and most of these changes are sexual and related to the sex glands and organs. Therefore, with activation of the gonads, the level of secretion of various hormones in the body increases and as a result, involuntary stimulation increases during this period. Also, due to these hormonal changes, many physiological functions, including the immune system, are affected, that can provide the conditions for Multiple sclerosis which is called MS. The MS is an inflammatory disease that the myelin sheaths of nerve cells in the brain and spinal cord are damaged. these damages can impair the ability of parts of the nervous system that are responsible for communication and new symptoms occur either as a recurrent or intermittently. However, its main mechanism is damage to the immune system or disruption of myelin sheath-producing cells and usually diagnosed based on the signs, symptoms, and results of medical tests. For this reason, this review examines the role of maturation in the risk of MS and its age, as well as its effect on exacerbating the severity of the MS disease.
\end{abstract}

Keywords: Multiple Sclerosis;Hormonal Changes;Maturation;Physiological Functions; Nerve Cells; Immune; Secretion; Muscle Growth; Genetic; Heredity

\section{Introduction}

Based on the set of physical and physiological changes in the human body that according to which the secretion of various hormones occurs, the child's body becomes an adult body.Most of these hormonal changes due to maturation create readiness, a sense of need, and the ability to have sex and reproduce [1]. The timing, processes, and signs of maturation vary from boy to girl. This process is sometimes accompanied by a mutation that called maturation mutation, and it is kind of rapid physical growth and usually occurs in early maturation, which eventually increases height, weight, and muscle growth[2].In some cases, these sexlinked hormonal changes can be associated with the risk of multiple sclerosis (MS). In addition, other hormonal changes that a person may experience during their lifetime can have a significant impact on the onset and progression of MS. Because maturation is the time of extensive hormonal changes in the body, depending on the scope of these changes, its effects which have been less studied in recent years can be vary. the reason for this may be the low probability of Occurrence of MS during maturation and the processes associated with abundant hormonal changes during this period of life.Genetic diversity also play the key role [3].

\section{Maturation Process and Its Symptoms}

Maturation is the period in which growing boys or girls are subjected to the process of it. In these changes, physical growth begins earlier than rational aspect and Suddenly many physical changes occur that may not be pleasant for people who are in maturing [4]. This period involves a series of stages that lead to fertility and the development of so-called secondary sexual characteristics in men and women and some biological and physical changes happen that can affect the social and emotional development of adolescents [5,6].Process of maturation that is 
completed over several years and leads to the end of childhood This physiological phenomenon occurs in boys later than in girls . usually this process occurs in boys between the ages of 11 and 16 and in girls between the ages of 9 and 13[7]. The speed of maturation in boys is lower than in girls, thats why the period of maturation and the completion of its symptoms in boys lasts longer than in girls[8].

Maturation changes include the growth of sexual organs, the onset of secondary sexual characteristics, and the attainment of fertility, while the composition of the body has also changed $[9,10]$. The changes are controlled by the Gonad hypothalamus and pituitary axis and are regulated by complex stimulatory and inhibitory factors[11]. The gonadotropin-releasing hormone ( $\mathrm{GnRH}$ ) secretion begins at about 5 to 6 months of age in boys and 3 to 4 years in girls and continues throughout childhood. Maturation begins with a steady increase in GnRH pulse release and ends within 3 to 4 years. GnRH also stimulates pituitary hormones (LH) and follicle-stimulating hormone (FSH), which acts on sexual desire and glands[11-13].The secretion of these hormones in boys stimulates the testicles to produce the male sex hormone testosterone[14]. These hormones cause changes in the size of the genitals and the growth of body hair, followed by sperm production and increased libido. Other signs of maturation in boys, often referred to as secondary sexual characteristics, include:

a. Testicular growth, secretion of sex hormones and increased sperm production

b. Penis growth

c. A change in the voice and its thickening or masculinity

d. Physical growth and physical changes.

e. semen coming out during sleep

f. Facial hair growth (beard and mustache)

g. Hair growth around the genitals

h. Hair growth in the armpits and other parts of the body

On the other hand, maturation is different in girls[15]. In general, girls reach maturation about 2 years earlier than boys. Race, climate, heredity, type of nutrition, cultural conditions, emotional and social relationships cause the change of maturation age in girls[16]. The first sign of maturation in girls is menstruation, which usually begins between the ages of nine and eighteen and the girls weigh about 50 kilograms (very thin girls are later regularized) [17]. On average, girls develop menstruation for the first time at the age of thirteen. after the pituitary gland matures begins to secrete hormones that stimulate the ovaries to produce female sex hormones, estrogen and progesterone[18]. These hormones cause physical changes such as breast and pelvic enlargement and the growth of pubic and axillary hairs, which in turn stimulate ovulation and menstruation[19].In terms of the body, as the bones and muscles of the body grow, especially the pelvis, and also due to the breasts growth, maturation mutations in girls can be seen quickly and in a short time[20]. Height gain usually lasts until the age of eighteen. Increased secretion of estrogen and progesterone is one of the causes of these changes.

Other signs of maturation in girls' secondary sexual characteristics:
a. Menstruation
b. Voice feminization
c. Breast growth
d. Increase and distribution of fat in the body
e. Hair growth around the genitals
f. Underarm hair growth

\section{Factors Influencing the Onset of the Maturation Process}

Several factors can play a major role in maturation, but the most important determinant of maturation is genetic factors [21]. For example, in a family whose first and second class members, such as the mother, sister, have begun to mature at the age of eleven to thirteen, the daughter of the family is likely to become an adult at the same age[22,23].0ther factors include environmental factors, habitat, racial and ethnic differences, nutrition and health, social ties, close family relationships like large families or living in small houses and specific cultural issues[24]. Studies have also shown that the variability of maturation is sometimes genetically determined to be up to $75 \%$, and includes the thyroid hormone receptor mediator in individuals, which is triggered by changes in gene extragenetic control during maturation[25].Extra genetics is the leading mechanism of the environmentthat communicates with genes. environmental factors and lifestyles also can affect the extra genetic regulation of genes and determine which gene is activated. Therefore, the known extra genetic changes in maturation can be our guide in understanding how the environment affects the onset of maturation. On the other hand, hormones such as ghrelin, leptin, and insulin send messages to the reproductive structure and affect the age of maturation[26].

\section{Challenges of Maturation Study and Multiple Sclerosis}

Specialists in the field of pediatric diseases usually use the sexual maturity rating scale to diagnose and determine the stage of maturation in girls and boys[27]. This scale is related to physical growth in children, adolescents, and adults, and determines the physical dimensions of growth based on primary and secondary sexual characteristics[28]. For example, breast size, genitals, testicular volume, and excess hair are examined. This scale was first defined in the 1960s and 1960s by James Tanner, a British pediatrician[29]. By considering natural variety and the time of maturity, people go through different stages of scale at different speeds. The degree of sexual maturity determines whether 
the patient is an adult or a child . so, dur to the condition, the appropriate instructions for their treatment can be applied [30]. This scale includes five steps to change the hair around the genitals, breast size in girls, and penis growth in boys[31,32]. The most important clinical evidence from the onset of maturation is breast enlargement and testicular enlargement, which can be evaluated by clinical examination or description by the individual[33].

On the other hand, the growth of pubic hair from parts of the body, such as the armpits, is not a good sign of maturation because it can be associated with increased levels of adrenal androgen production. For this reason, only the condition of the minaret in girls and testicular enlargement with the growth of acceleration of sperm in boys indicates the end of maturation for them[34]. Therefore, despite the numerous clinical trials and reports of people under study, the result of age relation and maturation changes is still challenging[35].

\section{Hormonal Changes and Its Effects on Immune System}

The immune system is the one of the most important part of the body that detects its own cells and molecules from aliens, such as germs and viruses and destroys the external factors. Sometimes, due to the similarity of the antigen of the intracellular to the non autothonous, the immune system attacks the its own cells. since the body's system secretes different types of hormones during puberty, these extensive changes can weaken the body's immune system[36].However, maturation can be physically and emotionally difficult. Sudden increases in hormones, rapid physical changes, and the formation of sexual organs can cause a lot of stress in the body, and this can cause adolescents to be particularly vulnerable to infections because the immune system is under severe pressure and it is trying to stabilize the situation. Due to the wide range and complexity of the impact of the maturation structure on the immune system, several studies also have been performed on laboratory animals[37].

The immune response is more towards to Th2 bias in the early postnatal period and in the next stage, there is an increase by an age related Th1 (IFN- $\gamma$ ).these studies show that Testosterone hormones decreases the level ofIL- 6 and leptin production while it can increase the secretion amount of C-reactive protein (CRP), $\mathrm{TNFa}$, adiponectin, and ghrelin and make extensive changes in body. Estradiol hormones also decreases IL-6 production and increases $\mathrm{TNFa}$, but in contrast with testosterone, stimulates leptin with high level while decreasing the secretion of adiponectin and ghrelin. As well as, sex hormone binding globulin (SHBG) has an opposite effect on CRP, IL-6 and TNFa compared with testosterone and estradiol. On the other hand, sensitivity to autoimmune neuro inflammation, which is triggered by an attack of self-reactive lymphocytes known as experimental autoimmune encephalomyelitis (EAE), increases in mice during maturation.So it can be very difficult to induce EAE before that. Female mice that have reached maturation are more susceptible to using the ovary in 3 to 5 weeks compared to mice in or before maturation[38]. But the extent, severity of the disease, and the number of white blood cells that are part of the immune system are similar. Lymph nodes and spleen glands proliferate more strongly in post-adult mice after stimulation with peptide proteolysis protein (PLP) $[39,40]$ and sensitivity to EAEreduced in antigen-providing cells (APCs) that were able to reduce CD4 + T response cells in pre-mature mice[41].

\section{The Relationship Between Maturationand Symptoms of Multiple Sclerosis}

A study of a comprehensive database in the United States found that of the highest number of cases in children with MS, two peaked cases were between the ages of 5 and 15 respectively[42]. This indicates the effect of sex hormone secretion and major physiological changes in the body on the risk of the contracting disease in childhood and adolescence[43].On the other hand, a retrospective study looked at the effects of maturation on 100 girls with MS who had it before the age of 18 . The study subjects were divided into three different groups based on the time MS started compared to the minaret time. The first group before menarche, the second group from 6 months before menarche to 6 months after menarche and the third group after menarche[44,45]. The age of the menarche was similar in all three study groups for the same conditions and this indicating that MS may not affect the age of the menarche. Studies show that MS begins 2 to 3 years after menarche and it is clear that extensive hormonal changes in the body during maturation may moderate the age at which MS begins[46].

Also, the relationship between menarche and recurrence risk in another study of children has been studied, so that out of 285 cases, premature age in maturation, especially in people with obesity, is directly related to the initial age of onset of MS in children[47]. In general, the effect of maturation on MS susceptibility is more challenging than other risk factors such as obesity, and in order to obtain more accurate information about the different stages of maturation, children with MS can have a cerebrospinal fluid (CSF) test and resonance imaging (MRI), which is used to justify the association with maturation[48].

\section{Maturation and Its Effect on Multiple Sclerosis Stages}

The observable characteristics of the disease may change with onset age of MS.Some symptoms may be more common in younger patients, or before the onset of maturation[49]. In a larger group, the age of onset of MS provides a clinical picture of the observed characteristics of the altered disease.in general , patients usually before 10 years were more likely to have encephalopathic and coordination symptoms at disease onset, whereas patients with more age were more likely to have cord events. also the Symptoms of impaired brain function at the onset of the disease are also more likely to occur in patients who are older[50].In addition to the possible effect of age on onset of visible MS characteristics, 
maturation may affect the risk of recurrence in children with the disease. Studies have shown an increase in the incidence of recurrence in patients divided into the second group compared to the third group of classifications. the results of which can be seen in Table 1[51].

Table 1: Incidence rate ratio of relapse in two period of time (Before and After Menarche).

\begin{tabular}{|c|c|c|c|c|}
\hline & $\begin{array}{c}\text { Pre } \\
\text { menarche }\end{array}$ & & $\begin{array}{c}\text { Peri } \\
\text { menarch }\end{array}$ & \\
\hline & $\begin{array}{c}\text { Incidence } \\
\text { rate ratio } \\
\text { (90\% } \\
\text { confidence } \\
\text { interval) }\end{array}$ & Value of $P$ & $\begin{array}{c}\text { Incidence } \\
\text { rate ratio } \\
(90 \% \\
\text { confidence } \\
\text { interval) }\end{array}$ & Value of $P$ \\
\hline Adjustments & $3(0.3,29)$ & 0.25 & $9(3.5,29.4)$ & 0.002 \\
\hline
\end{tabular}

In children with the first demyelinating events, including isolated transverse myelitis, optic neuromilitis, acute diffuse encephalomyelitis (ADEM), isolated optic neuritis, age after menarche was associated with a reduced risk of subsequent MS diagnosis[52]. In addition, the age of onset of the disease may be associated with the recovery of the first and second relapses, because due to physiological reasons, the complications of the disease in children improve better than in adults[53](Table1).

\section{Conclusion}

The observations have been crucial to an acceptable understanding from a clinical perspective when caring for younger patients, and play a key role in making rational decisions about treatment based on disease activity. It is also possible to discover more biological processes associated with adult MS and thus lead to new treatment strategies. According to studies, there is a clear relationship between MS and maturation. On the other hand, hormonal changes, obesity, genetics, environmental factors, and especially maturation, may affect the risk of developing MS. As a result, there is a possible link between maturation and MS-related activities and for further explore the facts in future studies, medical advice can be considered more seriously to get more accurate results from biologically accurate processes.

\section{References}

1. Kis B, Rumberg B, Berlit P (2008) Clinical characteristics of patients with late-onset multiple sclerosis. J Neurol 255(5): 697-702.

2. Krupp LB, Tardieu M, Amato MP, Banwell B, Chitnis T, et al. (2013) International Pediatric Multiple Sclerosis Study Group. International pediatric multiple sclerosis study group criteria for pediatric multiple sclerosis andimmune-mediated central nervous system demyelinating disorders: revisions to the 2007 definitions. Mult Scler 19(10): 12611267.

3. Nielsen NM, Harpsøe M, Simonsen J, Stenager E, Magyari M, et al (2017) Age at menarche and risk of multiple sclerosis: a prospective cohort study based on the Danish national birth cohort. Am J Epidemiol 185(8):712-719.
4. Chitnis T, Glanz B, Jaffin S, Healy B (2009) Demographics of pediatriconset multiple sclerosis in an MS center population from the northeastern United States. Mult Scler 159(5): 627-631.

5. Achiron A, Garty BZ, Menascu S, Magalashvili D, Dolev M, et al. (2012) Multiple sclerosis in Israeli children: incidence, an clinical, cerebrospinal fluid and magnetic resonance imaging findings. Isr Med Assoc J 14(4): 234-239.

6. Van Haren K, Waubant E (2013) Therapeutic advances in paediatric multiple sclerosis. J Pediatr 163(3): 631-637.

7. Chitnis T, Tardieu M, Amato MP, Banwell B, Bar Or A, et al. (2013) International pediatric MS study group clinical trials summit: meeting report. Neurology 80(12): 1161-1168.

8. Huppke B, Ellenberger D, Rosewich H, Friede T, Gärtner J, et al. (2014) Clinical presentation of pediatric multiple sclerosis before Puberty. Eur J Neurol 21(3): 441-446.

9. Pavone P, Pettoello Mantovano M, Le Pira A, Polizzi A, Giardino I, et al. (2010) Acute disseminated encephalomyelitis. A long-term prospective study and meta-analysis of the literature. Neuropediatrics 41(6): 246255.

10. Rejali M, Hosseini SM, Kazemi Tabaee MS, Etemadifar M (2016) Assessing the risk factors for multiple sclerosis in women of reproductive age suffering the disease in Isfahan Province. Int J Prev Med 7(1): 58.

11. Hernández Pedro NY, Espinosa Ramirez G, De la Cruz VP, Pineda B, Sotelo J (2013) Initial immunopathogenesis of multiple sclerosis: innate immune response. Clin Dev Immunol 2013: 413465.

12. Olsson T, Barcellos LF, Alfredsson L (2017) Interactions between genetic, lifestyle and environmental risk factors for multiple sclerosis. Nat Rev Neurol 13(1): 25-36.

13. Adil Harroud, John A Morris, Vincenzo Forgetta, Ruth Mitchell, George Davey Smith, et al. (2019) Effect of age at Puberty on risk of multiple sclerosis, Neurology 92(16): e1803-e1810.

14. Salehi F, Abdollahpour I, Nedjat S, Sahraian MA, Memari AH, et al. (2018) Uncovering the link between reproductive factors and multiple sclerosis: a case-control study on Iranian females. Mult Scler Relat Disord. 20: 164168.

15. Ingwersen J, Aktas O, Hartung HP (2016) Advances in and algorithms for the treatment of relapsing-remitting multiple sclerosis. Neurotherapeutics 13(1): 47-57.

16. Bove R, Chua AS, Xia Z, Chibnik L, De Jager PL, et al. (2015) Complex relation of HLA-DRB1*1501, age at menarche, and age at multiple sclerosis onset. Neurol Genet 2(4): e88.

17. Miller DH, Fazekas F, Montalban X, Reingold SC, Trojano M (2014) Pregnancy, sex and hormonal factors in multiple sclerosis. Mult Scler 20(5): 527-536.

18. Ramien C, Taenzer A, Lupu A, Heckmann N, Engler JB, et al. (2016) Sex effects on inflammatory and neurodegenerative processes in multiple sclerosis. Neurosci Biobehav Rev 67: 137-146.

19. Ingwersen J, Aktas O, Hartung HP (2016) Advances in and algorithms for the treatment of relapsing-remitting multiple sclerosis. Neurotherapeutics 13(1): 47-57.

20. Andrews LE, Liu GT, Ko MW (2014) Idiopathic intracranial hypertension and obesity. Horm Res Paediatr 81(4): 217-225.

21. Harroud A, Richards JB (2018) Mendelian randomization in multiple sclerosis: a causal role for vitamin D and obesity? Mult Scler Houndmills Basingstoke Engl 24(1): 80-85.

22. Salpietro V, Ruggieri M (2014) Pseudotumor cerebri pathophysiology: the likely role of aldosterone. Headache 54(7): 1229. 
23. Sheldon CA, Kwon YJ, Liu GT, Mc Cormack SE (2015) An integrated mechanism of pediatric pseudotumor cerebri syndrome: evidence of bioenergetic and hormonal regulation of cerebrospinal fluid dynamics. Pediatr Res 77(2): 282-289.

24. Shervin Badihian, Navid Manouchehri, Omid Mirmosayyeb, Fereshteh Ashtari, Vahid Shaygannejad (2018) Neuromyelitis optica spectrum disorder and menstruation. Revue Neurologique 174(10): 716-721.

25. Rubtsova K, Marrack P, Rubtsov AV (2015) Sexual dimorphism in autoimmunity. J Clin Invest 125(6): 2187-2193.

26. Gianfrancesco MA, Glymour MM, Walter S, Rhead B, Shao X, et al. (2017) Causal effect of genetic variants associated with body mass index on multiple sclerosis susceptibility. Am J Epidemiol 185(3): 162-171.

27. Balint B, Haas J, Schwarz A, Sven Jarius, Alexandra Fürwentsches, et al. (2013) T-cell homeostasis in pediatric multiple sclerosis: old cells in young patients. Neurology 81(9): 784-792.

28. Matarese G, Di Giacomo A, Sanna V, Graham M Lord, Jane K Howard, et al. (2001) Requirement for leptin in the induction and progression of autoimmune encephalomyelitis. J Immunol 166(10): 5909-5916.

29. Munger KL, Chitnis T, Ascherio A (2009) Body size and risk of MS in two cohorts of US women. Neurology 73(19): 1543-1550.

30. Day FR, Thompson DJ, Helgason H, Chasman DI, Finucane H, et al. (2017) Genomic analyses identify hundreds of variants associated with age at menarche and support a role for Puberty timing in cancer risk. Nat Genet 49(6): 834-841.

31. Beretta M, Bauer M, Hirsch E (2015) PI3K signaling in the pathogenesis of obesity: the cause and the cure. Adv Biol Regul 58: 1-15.

32. Procaccini C, Pucino V, Mantzoros CS, Matarese G (2015) Leptin in autoimmune diseases. Metabolism. 64(1): 92-104.

33. Munger KL, Bentzen J, Laursen B (2013) Childhood body mass index and multiple sclerosis risk: a long-term cohort study. Mult Scler 19(10): 1323-1329.

34. D'Hooghe MB, Haentjens P, Nagels G, T D'Hooghe, J De Keyser (2012) Menarche, oral contraceptives, pregnancy and progression of disability in relapsing onset and progressive onset multiple sclerosis. J Neurol 259(5): 855-861

35. Mokry LE, Ross S, Timpson NJ, Sawcer S, Smith GD, et al. (2016) Obesity and multiple sclerosis: a Mendelian randomization study. PLOS Med 13(6): e1002053.

36. Day FR, Ruth KS, Thompson DJ, Lunetta KL, Pervjakova N, et al. (2015) Large-scale genomic analyses link reproductive aging to hypothalamic signaling, breast cancer susceptibility and BRCA1-mediated DNA repair. Nat Genet 47(11): 1294-1303.

37. Chitnis T (2013) Role of Puberty in multiple sclerosis risk and course. Clin Immunol 149(2): 192-200.

\section{ISSN: 2574-1241}

DOI: $10.26717 / B J S T R .2020 .30 .004981$

Mostafa Mohammadi. Biomed J Sci \& Tech Res

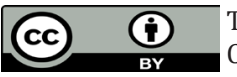

This work is licensed under Creative Commons Attribution 4.0 License

Submission Link: https://biomedres.us/submit-manuscript.php
38. Lulu S, Graves J, Waubant E (2016) Menarche increases relapse risk in pediatric multiple sclerosis. Mult Scler 22(2): 193-200.

39. Casper TC, Rose JW, Roalstad S, Emmanuelle Waubant, Gregory Aaen, et al. (2015) The US Network of Pediatric Multiple Sclerosis Centers: development, Progress, and Next Steps. J Child Neurol 30(10): 13811387.

40. Langer Gould A, Brara SM, Beaber BE, Koebnick C (2013) Childhood obesity and risk of pediatric multiple sclerosis and clinically isolated syndrome. Neurology 80(6): 548-552.

41. Lobstein T, Jackson Leach R, Moodie ML, Kevin D Hall, Steven L Gortmaker, et al. (2015) Child and adolescent obesity: part of a bigger picture. Lancet 385(9986): 2510-2520.

42. Bove R, Chitnis T (2013) Sexual disparities in the incidence and course of MS. Clin Immunol 149(2): 201-210.

43. Amirreza Azimi, Sara Hanaei, Mohammad Ali Sahraian, Mehdi Mohammadifar, Sreeram V (2019) Ramagopalan and Mahsa Ghajarzadeh, Age at menarche and risk of multiple sclerosis (MS): a systematic review and meta-analysis, BMC Neurology 19(1): 286.

44. Karussis D (2014) The diagnosis of multiple sclerosis and the various related demyelinating syndromes: a critical review. J Autoimmun 48-49: 134-142.

45. Ahlgren C, Odén A, Lycke J (2014) High nationwide incidence of multiple sclerosis in Sweden. PloS ONE (2014) 9: e108599.

46. Patsopoulos N, Baranzini SE, Santaniello A, Shoostari P, Cotsapas C, et al (2017) The multiple sclerosis genomic map: role of peripheral immune cells and resident microglia in susceptibility. BioRxiv 143933.

47. Gustavsen MW, Page CM, Moen SM, Bjølgerud A, Berg Hansen P, et al. (2014) Environmental exposures and the risk of multiple sclerosis investigated in a Norwegian case-control study. BMC Neurol 14: 196

48. Tina Roostaei, Philip L De Jager (2019) Epidemiology and Genetics. Clinical Neuroimmunology 1(4): 71-87.

49. Richard V, Pearse, Tracy L (2019) Young-Pearse, lost in translational biology: Understanding sex differences to inform studies of diseases of the nervous system. Brain Research 1722: 146352.

50. María C Ysrraelit, Jorge Correale (2018) Impact of sex hormones on immune function and multiple sclerosis development. Immunology 156(1): 9-22.

51. Bove R, Chitnis T (2014) The role of gender and sex hormones in determining the onset and outcome of multiple sclerosis. Mult Scler 20(5): 520-526.

52. Compston A, Coles A (2008) Multiple sclerosis. Lancet 372(9648): 15021517.

53. Waisman A, Liblau RS, Becher B (2015) Innate and adaptive immune response in the CNS. Lancet Neurol 14(9): 945-955.

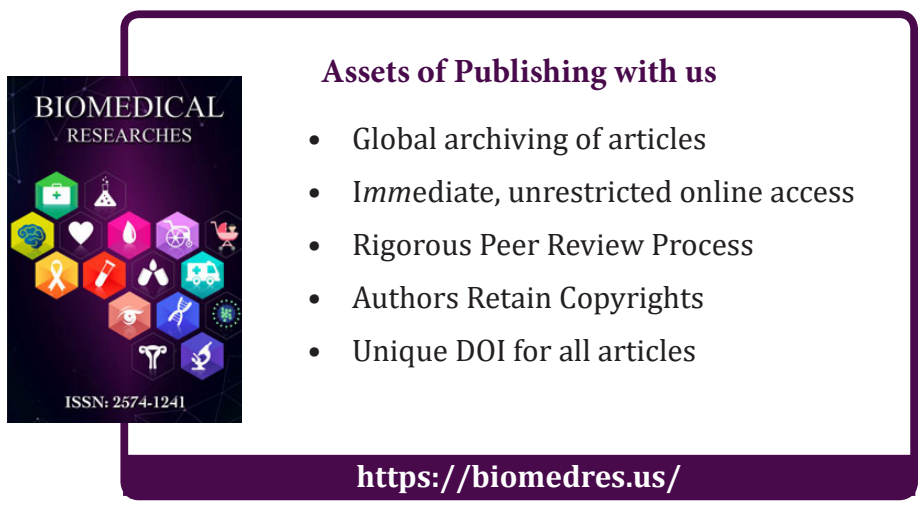

